mansasa

glyndŵn

Glyndŵr University

Glyndŵr University Research Online

Health Science

Nursing, Medical Sciences and Health

1-1-1999

\title{
Dietetic helpers in the community: the Bolton Community Nutrition Assistants Project
}

Lynne Kennedy

GlyndwrUniversity, 1.kennedy@glyndwr.ac.uk

JUbido

S Elhassan

A Price

J Sephton

Follow this and additional works at: http://epubs.glyndwr.ac.uk/chcr

Part of the Community Health Commons, Community Health and Preventive Medicine

Commons, and the Social Work Commons

Copyright (C) 1999 Blackwell. This is the author's final version of the work after peer review. The article was originally published in Journal of Human Nutrition and Dietetics in 1999 by Blackwell.

The definitive version is available at www.blackwell-synergy.com

\section{Recommended Citation}

Kennedy, L. A., Ubido, J., Elhassan, S., Price, A., and Sephton, J. (1999) 'Dietetic helpers in the community: the Bolton Community Nutrition Assistants Project'. Journal of Human Nutrition and Dietetics, 12(6), 501-512

This Article is brought to you for free and open access by the Nursing, Medical Sciences and Health at Glyndwir University Research Online. It has been accepted for inclusion in Health Science by an authorized administrator of Glyndŵr University Research Online. For more information, please contact d.jepson@glyndwr.ac.uk. 
DIETETIC HELPERS IN THE COMMUNITY: THE BOLTON COMMUNITY NUTRITION ASSISTANTS PROJECT

Kennedy, L. A. (Mphil). Lecturer Public Health Nutrition, Department of Public Health, The University of Liverpool; Ubido, J. Public Health Observatory, The University of Liverpool; Elhassan, S. (SRD);

Price, A. (SRD); Sephton, J. (SRD). Community Healthcare Bolton NHS Trust.

Author for correspondence:

Dr Lynne Kennedy MPhil, PhD, RPHNutr., HonMFPH., Academic Lead Medicine \& Health Sciences

Principal Lecturer

Prifysgol Glyndŵr Wrecsam

Glyndŵr University Wrexham

Mold Road, Wrexham, Wales. LL11 2AW.

Ffon/Tel: +44(0)1978 293112

Ffacs/Fax: $+44(0) 1978290008$

l.kennedy@glyndwr.ac.uk

Key Words: Community Nutrition; Lay Food Workers; Inequalities; Evaluation; Health Promotion; low income 
Abstract:

Study objective: To explore the role of 'Community Nutrition Assistants' (CNAs) in helping to increase coverage, by increasing access to local community dietetic services, and to bring about positive changes in the determinants of healthy eating, within low income areas of Bolton, England. Study design: A descriptive evaluation of programme development and field-testing (1995-1997) in the community. Non-experimental design.

Setting: community, less affluent neighbourhoods in Bolton, North West England.

Subjects: 1272 people in total, individuals and members of community groups, recorded as CNA contacts during 2 discreet monitoring periods; an opportunistic or purposive sampling strategy was used; subjects were randomly selected for group interview $(n=8)$ and telephone interviews $(n=41)$ out of a traceable sample of contacts $(n=94)$ over a randomly selected 1 month collection period.

Findings: compared with professional only service, CNAs efforts resulted in a fourfold increase in coverage of community nutrition services in the local community. CNAs demonstrated unique attributes, which positively influence their ability to work well with local people, but particularly those considered hard to reach. At least half the subjects interviewed reported positive behaviour changes such as changes to foods bought, cooking methods or foods eaten in the home.

Conclusions: This study has shown some benefits in training local people to work alongside existing community dietitians. This may help to reduce inequalities in health, address barriers to healthy eating experienced by low income families, and improve cost effectiveness. Before expansion continues on an ad hoc basis further research is needed to test generalisability, to assess health outcomes, and to quantify the value of using local people. The findings here are useful in guiding further developments. 


\section{Introduction}

Community based nutrition initiatives in the UK are increasingly popular. Research suggests that efficiency and effectiveness might be improved by using local people to compliment the work of Community dietitians (Kennedy et al 1998). In developing countries and in the USA, services provided by local people, as opposed to professional led, are considered more appropriate to the health needs of the local community. They are less expensive and foster self reliance and community participation. Lay persons, by their location and socio-cultural backgrounds, are considered more accessible by the people in their own communities. This can help overcome barriers to communication seen between 'clients' and health professionals and as a result improves overall coverage of the service, increases access for typically hard to reach members of the community, and contributes to improvements in health or its determinants (Eng et al, 1997).

In developing countries local people have long been recognised as a valuable resource and a major component of Primary Health Care (Berman et al, 1987). Non-professionals have been successfully used for more than 30 years by American welfare programmes such as the Women Infants and Children (WIC) Rush et al, 1988) and the Expanded Food and Nutrition Education Program (EFNEP) (Pickett, 1992; Chipman and Kendall, 1989). With the exception of the Food Leaders Scheme, 1942 to 1952, (Smith, 1992) promoting healthy eating at the community level in the UK has remained the domain of health professions, notably dietitians and in particular community dietitians. Involvement of local people as community nutrition assistants is a relatively new concept in the UK. Despite this the authors know of at least 8 similar projects.

More recently the potential role and value of employing dietetic helper grades has been recognised by the profession. Work is ongoing to establish guidelines and standards for implementation (BDA, 1998).

The role of dietary patterns in the development of major public health problems is widely accepted. And in the UK, like other developed countries, promotion of healthy eating is high on the public health agenda (Department of Health, 1992; Department of Health 1998). 
The present government is also committed to improving the health of the worst off in society and to reducing the inequalities in health and its determinants, including nutrition. In the North West region mortality and illness rates are higher than anywhere else in the UK. Social characteristics and lifestyles of the lowest income groups in the North West also correlate closely with the highest levels of mortality and ill health in the region (NWRHA, 1997). Nationally, achievement of nutrition targets amongst disadvantaged groups has so far proven difficult (Gregory et al, 1990; MAFF, 1996) with lower socioeconomic groups experiencing the greatest proportion of nutrition related risk factors (James et al, 1997).

To date much of the effort aimed at reducing health inequalities has been restricted to initiatives aimed at changing people's lifestyle or health related behaviour (Whitehead 1996). Previous health policy is partly responsible for the emphasis on individual ideology: "action to achieve health and nutrition targets involves dissemination of information about healthy eating and encouraging and enabling changes in the populations diet" (Department of Health, 1992). Not surprisingly then, nutrition education has been a focus of health professionals' remit, particularly community dietitians.

Research however, consistently shows that choices about food purchase and food consumption by low income families are influenced by factors other than health and nutrition knowledge (Dobson et al, 1995; Department of Health, 1996) and ignorance of healthy eating messages is not the main issue (HEA, 1989). Empirical research has shown that for low income groups nutrition education has a limited role (Kennedy and Ling, 1997; Kennedy et al, 1998) for reasons summarised in figure (1).

Wider social, structural and economic factors clearly have a mitigating effect on people's ability to adopt healthy eating advice. Interestingly, the effect of personal circumstances appears to be a cumulative one (Kennedy and Ling, 1997).

Dietary behaviour is a complex process and therefore requires a broader health promotion approach (Vaandrager et al, 1993). For health professionals working in regions like the North West of England, 
where health inequalities are most striking, the prospect of achieving national targets for nutrition remains a particular challenge (Flynn and Knight, 1998).

In the past, community dietitians have responded by developing more appropriate and effective means of achieving nutrition targets for low income households by addressing the wider issues involved and the barriers to change. The limitations of the traditional approach have been recognised and interest in more participatory approaches and in health promotion soon followed, for example: local initiatives, campaigning for healthy school tuckshops, establishing local food cooperatives, community cafes and cook and taste groups (NCHR, 1991; NFA, 1997).

Whilst innovative responses to the issue of food, income and health have been developed, few are actually evaluated (Williams and Dowler, 1994). Although worthy the main problem with local initiatives, however useful, is that they are resource intensive (Kennedy et al, 1998). The approach, largely non-directive, involves lengthy consultation and familiarisation with local communities. Progress therefore is slow; demanding a large proportion of health professional's time. Competing demands and pressure to undertake clinical work in general practice has further reduced the time available for health promotion or community nutrition work of this nature. Efficiency can be improved by involving lay people in doing time consuming community based work and needs assessment. As mentioned local people are best placed and more effective in identifying local health needs and encouraging communities to get involved in health promotion activities.

Experience has suggested that lay people working in their own communities will quickly gain a more accurate picture of the food and health needs of that community (Jackson and Parks, 1997). The underlying principal being that people indigenous to the community make more successful nutrition assistants than professionals. Effective implementation depends on careful matching between client groups and local persons trained as Community Nutrition Aides (CNAs) (Pickett, 1994; Chipman and Kendall, 1989). In developing countries community health workers are widespread and make a valuable contribution to the local primary health care system (Elder et al, 1992; Bender and Pitkin, 1987; Ennever et al, 1990; Chaulagia, 1993). Whilst in the USA, 'Para-professionals' have proved to be 
effective agents of dietary change (Pickett, 1994; Chipman and Kendall, 1989; Amstutz and Dixon, 1986). Implementation on a wide scale has yet to be evaluated in the UK.

Increasing health care costs and widening inequalities in health makes the use of non-professionals in the UK an increasingly attractive option to policy makers and purchasers of health care. Involving local people might be more effective and efficient. Coverage is likely to be increased as a greater proportion of the population is reached and access by individuals missed by conventional service delivery will be improved. The role of Dietetic Helpers in the clinical setting is currently monitored and professional guidelines are forthcoming. It is also doubtful that community dietitians can improve the nutrition situation in the poorest areas of the country without additional resources.

\section{The Bolton Community Nutrition Assistants Project}

Against this background researchers at the University of Liverpool have been examining ways of developing more effective and efficient practice. The feasibility of adopting health promotion principles to address food and health problems, by using a network of non-health professionals to assist with the more time consuming tasks such as accessing local community groups or individuals, has been evaluated (Kennedy and Ubido, 1998).

Bolton is a large town in the North West of England. The Community Dietetic service employs 3 (2 full time equivalent) Food \& Health Advisers (FHA's) and is renowned for its innovative approaches to promoting healthier food and nutrition.

The FHA's work mainly in disadvantaged areas to encourage increased use of services by hard to reach groups. The approach used is based on the principles of Health for All and health promotion as described by the World Health Organisation (WHO, 1978; WHO, 1986). The emphasis is not nutrition education but about helping people to overcome barriers to eating healthily such as access to healthier foods. One example of this is the network of Food Cooperatives. 
The current project aims to: further develop through a network of trained lay workers, Community Nutrition Assistants (CNAs), the work of the Community Dietetics Service.Their task is to explore and act on the food and health needs of local communities particularly those in disadvantaged areas, using the principles of community development.

Although not the first programme to look at using non-professionals as nutrition assistants in the UK, it is the largest and most comprehensively evaluated to date.

CNA's are trained to work in their own neighborhoods by developing skills needed to help local people to identify and respond to the food and health problems in their locality. The training focused on developing nutrition facilitators not nutrition experts. After which, continued support was available from the community dietetic services. The key stages of the project including the training programme are outlined in Figure (2).

Once trained CNAs receive remuneration for their work ( $£ 2$ hour) and are able to select the number of hours worked/income earned to avoid loss of welfare benefits. On a day to day basis the CNAs may be involved with:

- making initial contacts with members of the community or key people

- introductory talks to groups e.g. Young womens Hostel

- preparation and planning for practical activities e.g. Cook \& Taste

- providing healthy eating advice or supporting food related activities

- monitoring and evaluation

\section{Evaluation}

The project was externally evaluated using an illuminative or descriptive approach incorporating both formative and summative aspects. Figure (3) outlines the evaluation objectives and the key stages of the evaluation process divided into 4 levels over the three stages of the project (figure 3).

The overall aim of the research was to further develop through a network of trained lay people, namely Community Nutrition Assistants (CNA's), the work of the community dietetics service in Bolton. Their 
task is to explore and act on the food and health needs of local communities to promote healthier nutrition, using a community development approach.

As a qualitative study theoretical sampling was used, thus sampling was determined by the purpose of the research, mainly the evaluation questions. Sample size was determined by factors relating to: the type of questions asked; feasibility; and the non-directive approach used by the project. The work of the CNAs is based on community development and involvement, which depends on an opportunistic approach. Therefore, a purposive sample was used.

Not all contacts, in terms of nature and length, were suitable for obtaining peoples personal details. The CNAs admitted they were sometimes reluctant to ask for personal details because they felt this would be inhibitive. Simple guidelines were subsequently developed to minimise selective recording to help minimise any sample bias. CNAs were asked to request the names and a contact number, personal or organisation, for all individual contacts involving more than an exploratory interview. This was used to provide a traceable sample. Respondents were chosen, at random, from a list of 94 individuals or traceable contacts for a specified 'study' period, also randomly chosen, of 4 weeks.

Formative and summative evaluations were used to provide constructive feedback on process and to measure achievement of the objectives (figure (3). Success was measured in terms of improvements in service coverage; the development of nutrition initiatives aimed at, and actual changes in, the determinants of dietary related behaviour. Given the scope of the evaluation and the project timescale it was not useful to focus only on measuring health related behaviour.

Qualitative methods are less intrusive and were more appropriate for this type of setting. More than one data source was used to help improve the validity of our data. Variance that occurs in the data can be validated to reflect the trait being examined rather than any weakness in the data source. Also by rephrasing certain key questions we were able to check for internal validity. 
The impact of the CNA's work at the individual and community level was assessed using self reported data obtained from different data sources: telephone survey and a group discussion; interviews with FHA's; interviews with the CNA's; content analysis of work diaries kept by CNA and of FHA's. Standard proformas, partially pre-coded, were developed for the CNAs and the FHA's to help in recording their work time and to classify and describe the nature of CNA contacts during the two monitoring periods, totaling six months.

The interview method was selected because, compared with other methods such as diet diaries or Self Assessment Questionnaires, it expects relatively little time or effort from the recipient. Furthermore it allowed researchers to explore topics fully and to ask respondents to expand on reported behaviour changes, or to illuminate their answers with examples. Structured and open ended questions were devised together with relevant probes to elicit more detailed information. For example, If changes to cooking or food purchasing patterns were reported this information was checked further by asking respondents to describe how it had changed, to quantify the extent of change or to estimate the change in frequency of certain foods etc. Guidance notes and briefing was given to help standardise the interview procedure and to try and minimise variability between the two interviewers (researchers).

Questions were developed according to the evaluation objectives and consideration of the information needs of all the project stakeholders, including community members. The questions were adapted for their purpose: unstructured and semi-structured respectively. Opportunities for yes no answers were limited.

Data analysis involved: preliminary data reduction of qualitative responses and content analysis of this using coding frameworks according to existing procedures (Miles and Huberman, 1984; Strauss and Corbin, 1990). Quantifiable data was summarised using descriptive statistics or frequency tables. It was difficult to identify appropriate methods of measuring individual empowerment. CNAs were trained to respond to the food and health needs of their contacts, and so the nature of their work was varied, and unpredictable. Individual or community empowerment can be measured by monitoring the process used, for e.g. to (I) identify felt needs and (ii) how CNAs encouraged people to identify 
solutions to their nutrition situation. Again, qualitative information was collected during mentoring sessions and group support sessions. This was used formatively and solely as a basis for CNAs to reflect on the approaches used and to share good practice.

\section{Findings}

Evaluation of stages (1) and (2) looks in detail at the recruitment process, operational factors, the training programme and work experience (31). Early findings suggest that modifications to the training programme are needed, for example: to actively recruit CNAs from a wider ethnic and gender diversity to meet different needs; to clarify the role of the CNA at the recruitment stage; to extend the training programme, alternating between theoretical and practical sessions to allow trainees to relate the two.

Twelve applicants, eleven female one male, living in local neighborhoods in Bolton were recruited following formal selection process. Two failed to complete the training for valid reasons (relocation and employment). Ten completed the training course detailed in figure (2) with 7 qualifying for National Vocational Qualification (NVQ@stage A, level 2). Nine CNAs commenced work in the community under the supervision of the FHA's.

Evaluation of stage (3): according to the detailed work diaries, cross referenced with the FHA's records and mentor notes, the CNAs worked on average 5.5 hours per week. At least half of this time was spent working with members of the community or 'contacts'. In the first 4 quarter (Jan.-April '96), the diaries of 8 CNAs were monitored. More than 200 (244) contacts were made during this period, on average 31 per CAN. At this stage the data did not differentiate between a group and an individual contact, therefore a contact could represent work with a single person or a community group, and the total number of individuals is unavailable.

By the second quarter period (Nov. '96; Jan. -March '97) only 6 of the original 10 CNA's remained. Although the number of CNAs in the network had decreased the total number of hours worked by CNAs remained constant. By the second quarter the CNAs became more effective, arranging actual 
food related events rather than needs assessment. Each CNA developed a portfolio of activity according to local needs, aimed at improving the local nutrition situation.

By the second period CNAs were recording data on the numbers of people representing a contact. A total of 191 contacts, totaling 1,028 individuals were reported for this period. An average of 260 people per month came into contact with the CNA network $(n=6)$ and the community nutrition services. Individual CNA's were contacting approximately 37 individuals or groups each per month. After one year, and all things equal, individual CNAs were making 4 times as many contacts than the FHA's for the same period, even when compared with data for previous years.

Compared to the FHA's the CNAs adopted more flexible working patterns, working from home within the local neighborhood and working at different times of the day or week. This meant that they could be more accessible to local people of groups. One advantage of this was their unique ability to access typically hard to reach groups, such as: the homeless; hostels for young mothers; the elderly; young adults; and unemployed. The main types of groups or individuals in contact with CNAs are listed in table (1).

The CNAs all had a good knowledge of their neighborhoods, about the groups that already existed and of the type of food and health issues locally. This was useful in helping the CNAs to understand their 'clients' and to shape their approach. CNAs showed an ability to persevere with difficult groups and to work using more informal, intensive, and personal style reserved for a community development approach.

The types of activities developed by CNAs are outlined in table 2 . Nearly $3 / 4$ ( $72 \%$ ) of all contacts involved some form of organised food and health activity such as cook and taste (food skills) sessions or groupwork on topics for e.g. healthy eating on a limited budget (table 2). A typical CNA might assist individuals to interpret dietary advice from their GP, by advising on shopping or cooking tips to adopt a low fat diet. Helping communities to establish food cooperatives in areas where access to fruit and vegetables is limited. Supporting parent groups in campaigning for healthier school tuck shops. Taking 
practical advice on healthy eating to young teenage mums in temporary accommodation and/or homeless hostels.

\section{Summative evaluation:}

During each 4 month monitoring period a total of 244 and 191 contacts were recorded. Information on the number of individuals was only available for the second period: 1,028 individuals. Only a proportion of these contacts $(n=94 / 244)$ had been in contact with a CNA for "more than a brief exploratory session', in the month chosen for sampling, and therefore met the inclusion criteria. Of these $50 \%$ (8 and 41) took part in the focus group and telephone interviews respectively.

Overall, more than half $(59 \%, \mathrm{n}=41)$ the respondents randomly selected for telephone interview said they had made changes to their eating habits as a result of taking part in activities linked to the project (fig. 4). When cross checked against the type of foods bought, 59\% (n=41) also reported changes to purchases of more healthier foods for the household, such as using low fat spreads, eating more bread, buying more pasta, using oven chips.

Again, half the respondents claimed that they had made changes to their cooking practices, mostly to start grilling and baking rather than frying foods. The types of foods or cooking practices considered by participants as 'more' and 'less healthy' were checked.

This was cross checked during the interviews. Respondents were asked to give more details on the reported changes to their diet since seeing the CNA. Although retrospective data has its limitations it was possible to check for consistency in self reported changes. Respondents volunteered more detailed information, for example "I used to serve chips 5 days a week - whereas now its about 2 or 3, the rest is noodles or salads"; "he (husband) used to get takeaways, pies pasties for his lunch - now I give him packed lunches, sandwiches, every day”; "we all have semi-skimmed milk now”

When asked what factors had influenced these changes, more than half the respondents identified without any prompting the CNA as having a positive role in initiating these changes (fig.5). This was 
explored further through their response to statements about their involvement with the CNA and the effect on their attitudes towards healthy eating or their ability to apply healthy eating advice (fig.6) Satisfaction with the service provided by the CNAs was high with $87 \%$ of respondents rating the service provided by the CNAs (scale 1-5) as very good or good. The CNAs practical approach and time available to deal with more practical issues was cited by respondents as the reason for this; "most people will tell you what to eat - but CNAs show you what to do"

The majority of respondents $(77 \%)$ preferred having a local person rather than a health professionals to fulfill this advisory role, because they were perceived as more approachable, easier to access and to show greater empathy: "they can communicate better, they know more about everyday life"; "people trust someone they know”; "it comes over better from someone our level-someone who knows the problems of finding something the kids will eat, and cater for all tastes on a budget. For a professional, money is not a problem"

This type of response was reiterated during the interviews with the FHA's: "they contact such a wide variety of people, and the quality of their work is good - they are much more approachable-people contact them who would never dream of approaching a dietitian”; “...they know where the opportunities (for initiatives) might be and where to look for them"

\section{Discussion}

The work in Bolton provides some insight into benefits to be gained from using a skill mix of Community Dietitians and of local people trained as CNAs. In the UK, the notion that 'professional knows best' is deeply entrenched in society and its value system. The cultural, social and educational differences observed between 'professionals' and 'lay' people serve to perpetuate this notion and its effect of promoting helplessness. This work also illustrates how local people have unique attributes, which are helpful in reducing the barriers between health professionals or health services and local communities. Their ability to relate and to empathise with fellow members of the community; a concept known as 'homophile' is essential to gaining the trust and cooperation of local people. As a result of this the people they contact are more likely to participate in local health services such as community dietetic 
services. Moreover the type of people contacted are not just the typical 'worried well' but more of those people at higher risk of nutrition problems, such as the socially excluded: homeless, single parents and travelling community can be reached. Nevertheless there is little empirical work that supports the view that this feature contributes to effectiveness, in terms of dietary change (34).

Using local people not only acknowledges the valuable contribution of lay people, their interpretations of health, but also promotes self help, it is a first step in developing peoples' capacities to help themselves. There is a fine balance however between homophile and perceived credibility and as such the approach is not without its problems: one must ask at what point is the boundary between Lay person and para-professional and professionals crossed? Or what happens when the boundary becomes blurred? At what point is a trained local person no longer perceived by their community as 'one of us'? Research in America suggests that more emphasis should be placed on preserving the indigenous or original values of the 'aide', to protect this feature, than on training in specific knowledge (Eng et al, 1997).

In the UK community nutrition initiatives have an important role. Nevertheless they are criticised for being ad hoc, for the lack of systematic evaluation, use of inappropriate indicators, and particularly for their inability to reach a significant proportion of the local population. In terms of public health, small changes at the population level can produce significant improvements in health; therefore initiatives which reach limited numbers have little value. The findings here suggest that coverage can be increased using local people: compared with a FHA the number of contacts achieved by each CNA were on average four times as high. With planning this could be developed further. In terms of cost, it is much more efficient to employ a network of CNAs to assist and support a dietetic or nutrition expert on a professional grade than it is to allow Community Dietitians to continue diluting their efforts by engaging in timely community organization or development work.

The next level of success is the quality of the contacts. CNAs will be judged by the nature of their work and the outcomes or impact produced. The data used here is mainly self reported. The authors acknowledge there are limitations in the study design and are therefore cautious in making 
generalisations. Nevertheless, triangulation at each stage should help to restore confidence in the findings. We report that CNAs who receive basic training are capable of initiating certain nutrition initiatives in the community without the support of professionals. These initiatives are those time consuming activities that Community Dietitians need to do but have increasingly less time for. For example, participatory and hands on work, such as cook and taste groups and the preparation involved in running these (shopping for foods, researching recipes, collecting equipment, finding suitable venues, and basic cooking skills). The authors recommend that effectiveness and efficiency of CNAs warrants further investigation, preferably using a more controlled study design possibly involving several centres.

The authors recognise however; that a firm policy on what a CNA should not attempt is necessary. As are clear guidelines on when CNAs should refer clients or seek support on matters from the FHA's. In Bolton, CNAs were not expected to give formal talks on healthy eating or to give individual dietary advice. Guidelines for Dietetic Helper grades are currently under consideration and this role needs to be considered in community dietetics, where there is greater opportunity for unsupervised contact between CNAs and the public.

Despite having a non formal education role CNAs were still able to influence behavioural factors. According to CNA contacts the work of the CNAs was considered valuable in helping them to adopt a healthy diet by addressing some of the constraints such as low income or access to healthier foods. Compared with professionals CNAs were considered helpful because they understood the difficult circumstance people faced and as such could suggest ways of preparing a healthy diet, which was realistic and credible.

Again criticisms raised by research highlight the danger of placing too much emphasis on the concept of using local people. Concern exists over using non-nutritionists in nutrition related programmes because of a risk they might disseminate incorrect or misleading information. Furthermore, constant referral or refrain from dealing with client's nutrition specific questions might undermine their own effectiveness 
More recent developments in the role of Dietetic Helpers within the profession including support from the professional body might help to overcome any resistance from health professionals over the use of non-nutritionists. Nevertheless care must be taken to evaluate these issues in the UK setting.

\section{Conclusion:}

Community Nutrition Assistants have a potential contribution to make to reducing inequalities in health by increasing coverage and facilitating access to services such as community dietetics in less affluent areas. Increased access to credible information and support could also help individuals and communities to address the social and structural barriers to healthy eating and to achieve better health. This approach may result in potential public health, social and economic benefits and therefore warrants further study. If successful, this model will have an important impact on the delivery of nutrition and dietetic services in the UK into the next millennium.

\section{Acknowledgements:}

The project is grateful to The North West Regional Health Authority for their financial support, with additional support from Community Healthcare Bolton NHS Trust. The project also wishes to thank members of the community and the CNAs for their continued commitment; Dr Alex Scott -Samuel, Senior Lecturer, and Ann Lockhart, Department of Public Health, The University of Liverpool. 


\section{References:}

Amstutz, M.D., Dixon, D.L. (1986) Dietary changes resulting from the Expanded Food and Nutrition Education Programme.J.Nutrition education. 18 :55-60.

Bender, D.E., Pitkin, K. (1987) Bridging the Gap: The village health worker as the cornerstone of the primary care model. Soc.Sc.Med. 24, No 6, 515-528.

Berman. P.A., Gwatkin, D.R., Burgher, S.E. (1987) Community-based healthworkers: Head start or false start towards health for all? Social Science Medicine; 25 (5): 443-459.

British Dietetic Association (1998) Report of the generic workers/dietetic helpers working party (13/05/98). British Dietetic Association, Birmingham.

Chaulagai, C.N. (1993) Urban community health volunteers. World Health Forum 14 16-19.

Chipman, H., Kendall, P.A. (1989) Twenty Years of EFNEP: Changes and Challenges. Journal of Nutrition Education 21, (6).

Contento, I., Balch, G., Bronner, Y., Lytle, L., Maloney, S., Olson, C., Swadener, S. (1995) The effectiveness of nutrition education and implications for nutrition education policy, programs, and research: a review of research. Special Issue. J. Nutrition Education 27: 6.p321.

Department of Health (1992) The Health of the Nation - A Strategy for Health in England. London: HMSO.

Department of Health (1996) Low income, food, nutrition and health: strategies for improvement A report by the Low Income Project Team for the Nutrition Task Force London: HMSO.

Department of Health (1998) Our Healthier Nation. London: HMSO.

Dobson, B., Beardsworth, A., Keil, T., Walker, R. (1995) Diet, Choice \& poverty: social cultural and nutritional aspects of food consumption amongst low income families. London: Family Policies Study Centre.

Elder, J.P., Louis, T., Sutisnaputras, O., Sulaeiman, N.S., Ware, L., Shaw, W., de Moor, C., Graeff. (1992) The use of diarrhoeal management counselling cards for community health volunteer training in Indonesia: the Health Com Project. Journal of Tropical Medicine and Hygiene 95, 301-308.

Eng, E., Parker, E., Harlan, C. (1997) Lay health advisor intervention strategies : a continuum from natural helping to paraprofessional helping. Health Education and Behviour Vol 24 (4); 413-417. August 1997.

Ennever, O., Brooks, S., White, S. (1990) Assessment of Community Health Aides. W.I.Med.J. 39:153160.

Flynn, P., Knight, D. (1998) Inequalities in health in the North West Warrington:North West Region NHS Executive.

Gregory, J., Foster, K., Tyler, H., Wiseman, M. (1990) The dietary and nutritional survey of british adults. Office of Population Cencuses and Surveys, Social Survey Division.London:HMSO.

Health Education Authority (HEA) (1989). Diet, Nutrition and Healthy Eating in Low Income Groups. London: HEA.

Jackson, E., Parks, C. (1997) Recuritment and training issues from selected lay health advisor programs among african americans : a 20 year perspective. Health Education and Behaviour, Vol 24 (4); 418-431. August 1997. 
James, W.P.T., Nelson, M., Ralph, A., Leather, S. (1997) The contribution of nutrition to inequalities in health. BritishMedical Journal 314,1545-49.

Kennedy, L.A., Hunt, C., Hodgson, P. (1998) Nutrition education program based on EFNEP for low income women in the United Kingdom : Friends with Food. J.of Nutrition Educatio. 30; (2) 89-99.

Kennedy, L.A., Ling, M. (1997) Nutrition education for low income groups - is there a role? In: Kohler, B.M., Feichtinger, E., Barlosius, E., Dowler, E. (eds.) (1997) Poverty \& Food in welfare societies. Berlin: Edition Sigma, 349-362.

Kennedy, L.A., Ubido, J. (1998) Evaluation of the Communiy Nutrition Assistant Food \& Health Training Project, Bolton. Liverpool:The University of Liverpool.

Miles, M.B., Huberman, A.M. (1984) Qualitative Data Analysis - A Sourcebook of New Methods. California: Sage Publications.

Ministry of Agriculture Fisheries and Food. (1996) National Food Survey, 1995. London: HMSO.

National Community Health Resource (NCHR). (1991) Community Health Initiatives \& Food: Information Pack. London: NCHR.

National Food Alliance (1997) National database on food \& low income projects. NFA 5-11 Worship Street London EC2A 2BH. 1997. correspondence.

North West Regional Health Authority (NWRHA) (1997) The Health of the North West of England: The report of the regional director of Public Health 1996-97. The University of Liverpool.

Pickett, A.L. (1994) The paraprofessional movement an update. Social Policy 40-43.

Rush, D., Alvir, J., Kenny, D., Johnson, S., Horvitz, D. (1988) The national WIC evaluation: evaluation of the special supplemental food program for Women Infants and Children. III Historical study of pregnancy outcomes', American Journal of Clinical Nutrition 48,412 -28

Smith, D. (1992) The Food Leaders Scheme 1942-52. In Prisk EM (Ed) (1992) The Urban Context. Proceedings of the XII International Home Economics and Consumer Studies Research Conference. Vol 1. Liverpool John Moores University (pp.16-19)

Strauss, A.L., Corbin, J. (1990) Basics of Qualitative Research. London: Sage Publications.

Vaandrager, H.W., Koelen, M.A., Ashton, J.R., Colomer, C. (1993) A four-step health promotion approach for changing dietary patterns in Europe. European Journal of Public Health, 3,193-198.

Whitehead, M. (1996) Tackling inequalities : a review of policy initiatives. In: Benzeval, M., Judge, K., Whitehead M. (1996) Tackling Inequalities in Health. London: Kings Fund.

Williams, C., Dowler, E.A. (1994) Identifying successful local projects and initiatives on diet and low income: a review of the issues. A working paper for the Nutrition Task Force Low Income Project Team, Department of Health. London: London School of Hygiene \& Tropical Medicine.

World Health Organisation (1986) Ottowa Charter for Health Promotion. Journal of Health Promotion $1,1-4$

World Health Organisation. (1978) Alma -Ata 1978: Primary Health Care. Geneva: World Health Organization. Health For All series, No.1. 
Figure (1): reasons why nutrition education has a limited role for low income groups $(17 ; 18)$

- traditional approaches to nutrition education have shown limited success in changing food consumption patterns of low income households

- the main barriers to change is not ignorance of nutrition but the sum effect of social, cultural and economic factors

- the unidimensional model of knowledge attitudes and behavior is too simplistic

- the combination and interrelationship offactors has a more powerful effect on the individuals ability to exercise informed choice

- nutrition education is clearly only part of the solution

- even using more contemporary methods of nutrition education people with limited resources are less likely to adopt recommended dietary changes unless other factors are also dealt with

- More Comprehensive approaches are needed

- evaluation of the effectiveness of nutrition prevention and health promotion work at the community level is urgently required

(Source: Kennedy and Ling, 1997; Kennedy et al, 1998) 
Figure (2 ) Key Stages of the Bolton CNA project \& Training Programme

(1) CNA recruitment --> (2) Induction --> Training programme --> (3) Community based training $-->$ monitoring and support

The CNA training programme:

The training consisted of 10 sessions each lasting 3 hours.

Informal pre-course meeting/lunch

Week $1 \quad$ Introduction and getting started

Week 2 Getting to know the community

Week 3 Communication skills

Week $4 \quad$ Food and Health (knowledge)

Week $5 \quad$ Working with individuals and groups

Week $6 \quad$ Working in a multi-cultural setting

Week $7 \quad$ Food and health topics/issues (resources/activities)

Week $8 \quad$ Practical cooking and food hygiene

Week 9 Programme planning and evaluation

Week 10Course review and summary 
Figure 3: key features of the evaluation framework

The objectives of the evaluation are to:

- compare the efficacy and cost-effectiveness of community dietitians and CNAs in achieving changes in the determinants of food consumption in disadvantaged neighbourhoods

- explore the feasibility of establishing a network of CNAs

The 4 Evaluation Levels

Level $1 \quad$ Training programme evaluability

Level $2 \quad$ Layworkers- skills and characteristics required

Level $3 \quad$ Impact on service delivery

Level $4 \quad$ Impact at the community level

The 3 stages of evaluation:

Stage $1 \quad$ Planning, programme development and recruitment

Stage 2 Layworker training and preliminary field work

stage $3 \quad$ Community work / mentoring/ evaluation

- identify the cost savings and other benefits to the NHS 
Table 1: Breakdown of CNA contacts according to groups/settings, during two monitoring periods*

\begin{tabular}{|c|c|c|}
\hline Contact type & $\begin{array}{r}\text { Number } \\
\text { of } \\
\text { contacts }\end{array}$ & $\%$ \\
\hline School & 19 & 11.7 \\
\hline Young people & 6 & 3.7 \\
\hline Tots/mums & 8 & 4.9 \\
\hline General population & 75 & 46.0 \\
\hline Food coop & 4 & 2.5 \\
\hline Elderly & 8 & 4.9 \\
\hline $\begin{array}{l}\text { Socially } \\
\text { disadvantaged }\end{array}$ & 30 & 18.4 \\
\hline Ethnic minority group & 1 & 0.6 \\
\hline Slimming group & 5 & 3.1 \\
\hline Professionals ${ }^{\star * *}$ & 3 & 1.8 \\
\hline School parents & 4 & 2.5 \\
\hline Total & 163 & 100.0 \\
\hline \multicolumn{3}{|c|}{$\begin{array}{l}\text { (NB: a reminder that one group is counted as one } \\
\text { contact) }\end{array}$} \\
\hline \multicolumn{3}{|c|}{ *(Nov. 1996, Jan-Mar 1997) } \\
\hline \multicolumn{3}{|c|}{$\begin{array}{l}{ }^{* *} \text { refers to groups or individuals living in deprived } \\
\text { areas, classified as such by census information; it also } \\
\text { included those who were living in temporary } \\
\text { accomodation, hostels, childrens homes and travellers. }\end{array}$} \\
\hline
\end{tabular}


Table 2: Type of activity undertaken during a contact with a CNA over the two monitoring periods *

\begin{tabular}{|c|c|c|}
\hline Activity & Number & $\%$ \\
\hline $\begin{array}{l}\text { Initial contact with } \\
\text { group/needs } \\
\text { assessment }\end{array}$ & 5 & 3.0 \\
\hline $\begin{array}{l}\text { Initial contact with } \\
\text { individual/needs } \\
\text { assessment }\end{array}$ & 11 & 6.6 \\
\hline $\begin{array}{l}\text { Discussion on food } \\
\text { issues }\end{array}$ & 81 & 48.5 \\
\hline Cook \& taste session & 40 & 24.0 \\
\hline Display & 2 & 1.2 \\
\hline $\begin{array}{l}\text { Resource based } \\
\text { activity }^{\star *}\end{array}$ & 22 & 13.2 \\
\hline Shopping & 6 & 3.6 \\
\hline Total & 167 & 100.0 \\
\hline
\end{tabular}


Figure 4: Reported behaviour changes since seeing the CNA

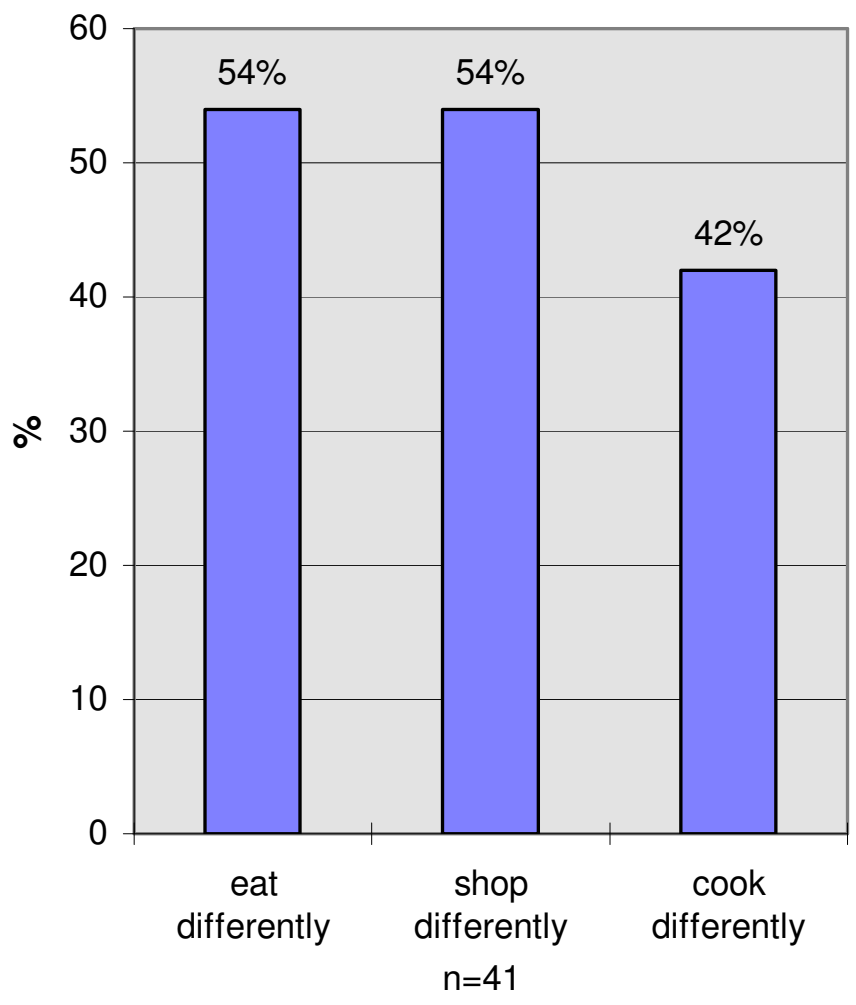


Figure 5: 'Would the changes have happened without seeing the CNA?'

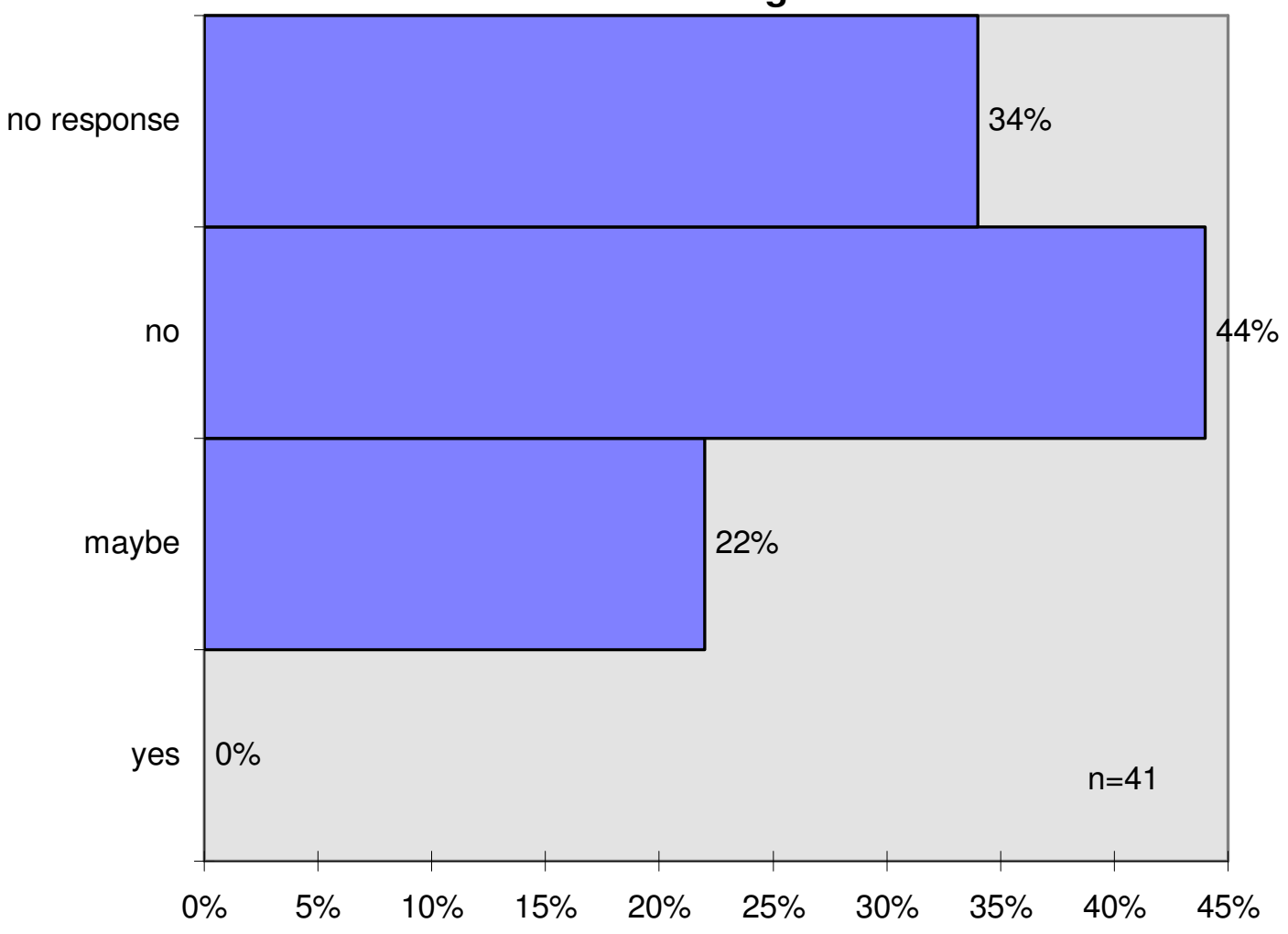


Fig 4 : Percentage of respondents who 'Agreed Strongly' or 'Agreed' with statements relating to contact with a CNA

(1) Since seeing the CNA, I think more often about healthy eating and how it affects my familys health $(39 \% ; 22 \%)$

(2) Since seeing the CNA, I take more interest in issues about healthy eating $(42 \% ; 20 \%)$

(3) I would definately say that I can now prepare a healthy diet for my family $(49 \% ; 15 \%)$ 